\title{
THE FE ANALYSIS AND VARIATION OF COMPOSITE TOP HAT SHAPED BEAM
}

\author{
DAVID Petr ${ }^{1}$, PADOVEC Zdeněk ${ }^{1}$, ZÁMEČNÍKOVÁ Tereza ${ }^{1}$, SEDLÁČEK Radek ${ }^{1}$
}

\author{
${ }^{1}$ CTU in Prague, Faculty of Mechanical Engineering, Department of Mechanics, \\ Biomechanics and Mechatronics, Technická 4, 16000 Praha, Czech Republic, \\ e-mail:david.petr7@gmail.com,zdenek.padovec@fs.cvut.cz
}

\begin{abstract}
The main goal of this work is to provide a composite alternative to an already existing beam which has top hat cross section. The main part of this work is focused on using the finite element method to solve the problem. Firstly, a duralumin version will be used to calibrate the computation, then the problem will be solved for different options of slightly adjusted geometry. The computation itself will include general static analysis as well as analysis of buckling.
\end{abstract}

KEYWORDS: Composite, Composite beam, Top hat shaped beam, Buckling, Finite element method

\section{Introduction}

Composite is a modern and progressive material, in that a composite is a highly customizable and one can set the number of layers, their orientation, and on top of that a designer can choose from a variety of matrix materials as well as fiber materials like carbon, glass or even natural fibers and biopolymers, which are friendly to the environment [1].

In this work we focus on analyzing a top hat - shaped beam, which reinforces door of an aircraft. The original beam has a prismatic top hat cross section, which is to be replaced with a slightly different geometry, in order to reduce the overall displacement in the model. Two ways of modeling composites are presented and compared (firstly a model with homogenized properties using the rule of mixtures and classical lamination theory [2, 3], and secondly a model created with actual lamina). All computations are done for all different types of geometry using the finite element method solver Abaqus.

The composite fabric used in this model consists of carbon fibers in polyphenylene sulfide matrix in composition of $5 \mathrm{H}$ satin. There will be ten layers in this composite in following configuration $\left[[(0,90) /( \pm 45)]_{2} /(0,90)\right]_{\mathrm{s}}$. Index s indicates, that the mentioned layers are present as well symmetrically with respect to the longitudinal axis of the composite. The index 2 says, that the layers $[(0,90) /( \pm 45)]$ appear twice after each other. With thickness of one layer being $0.31 \mathrm{~mm}$, the whole composite will be $3.1 \mathrm{~mm}$ thick. The fabric's and duralumin's mechanical properties are in Table 1 [4].

The direction of axis to which material properties are referred to is as follows: the $x$ axis is lead along the length of the beam, or in the direction of the $l$ dimension (see Fig. 1). The $y$ axis is perpendicular to the $x$ axis and circumvents the top hat shape. Finally, the $z$ axis is in the direction of the thickness of the beam (see Fig. 1, $\mathrm{z}$ axis is represented by the red arrows). 
Table 1 Mechanical properties of C/PPS 5H satin fabric and duralumin [4]

\begin{tabular}{|c|c|c|c|c|c|c|}
\hline Material & $\begin{array}{c}\boldsymbol{E}_{\mathbf{x}}=\boldsymbol{E}_{\mathbf{y}} \\
{[\mathbf{M P a}]}\end{array}$ & $\boldsymbol{E}_{z}[\mathbf{M P a}]$ & $\boldsymbol{G}_{\mathbf{x y}}[\mathbf{M P a}]$ & $\boldsymbol{G}_{\mathbf{x z}}=\boldsymbol{G}_{\mathbf{y z}}[\mathbf{M P a}]$ & $\boldsymbol{v}_{\mathbf{x y}}[-]$ & $\boldsymbol{v}_{\mathbf{y z}}=\boldsymbol{v}_{\mathbf{x z}}[-]$ \\
\hline $\begin{array}{c}\text { C/PPS 5H } \\
\text { Satin - } \\
\text { homogenized }\end{array}$ & 47427 & 11000 & 15166 & 4000 & 0.26 & 0.26 \\
\hline $\begin{array}{c}\text { C/PPS 5H } \\
\text { Satin - one } \\
\text { layer }\end{array}$ & 58000 & - & 4100 & 4100 & 0.05 & - \\
\hline Duralumin & 73000 & 73000 & 27443 & 27443 & 0.33 & 0.33 \\
\hline
\end{tabular}

\section{Creating the model}

The most loaded top hat beam was taken out of a global door assembly. The beam itself can be seen in Fig.1. The dimensions of the beam in Fig. 1 are in millimetres.
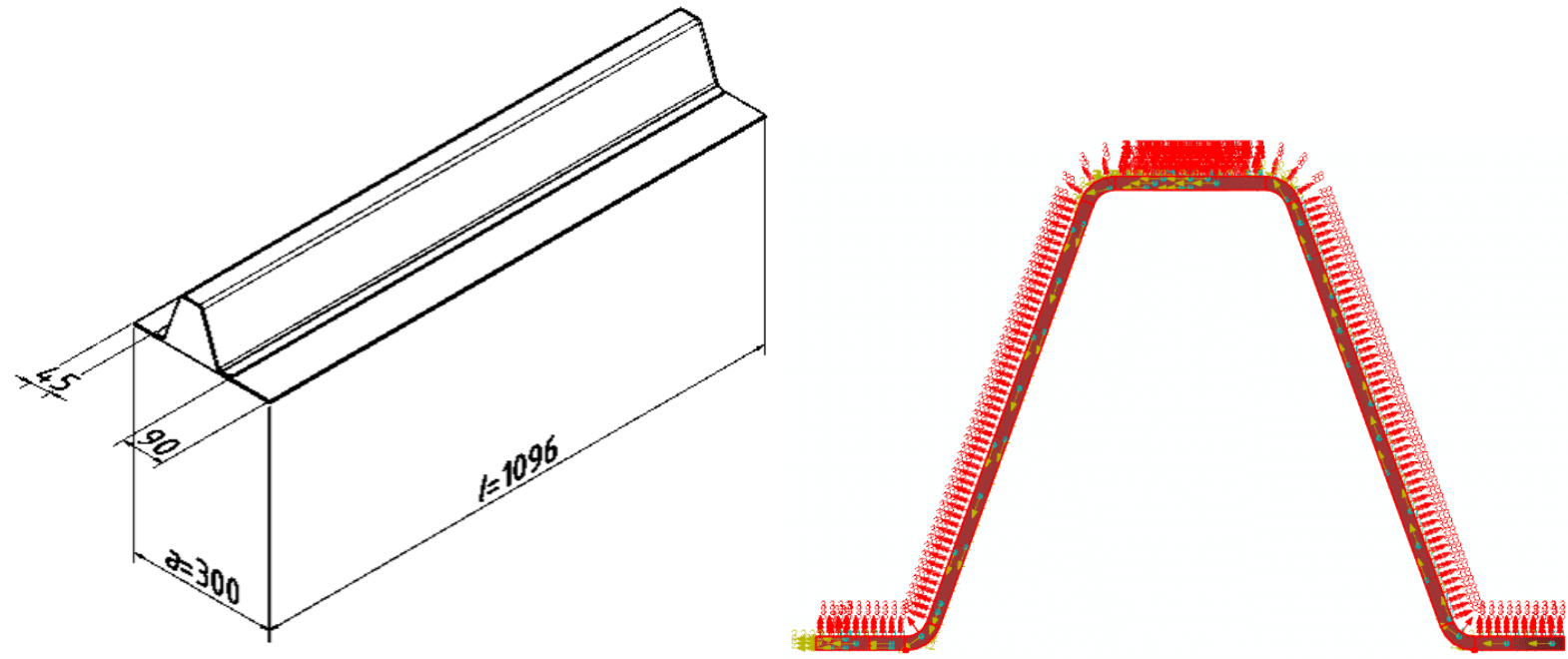

Fig. 1 Top hat - shaped beam (left), and in the right direction of axis $\mathrm{z}$ (in red) and y (along the top hat profile - yellow)

The computing area is reduced to a cutout of the skin panel with the beam (Fig. 1 on the left). The loading force used in the model is computed from the known reaction forces in the support beams connected to the top hat (in Fig. 2 labeled as "Stop" with green color).

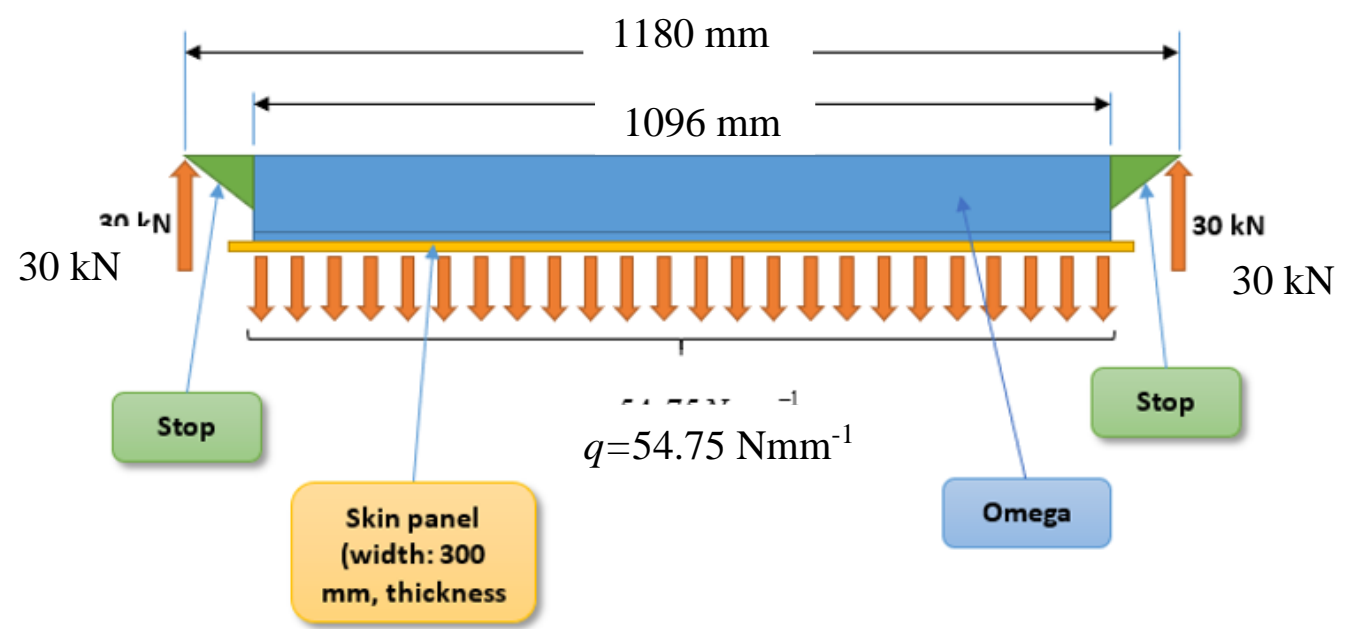

Fig. 2 Loading and reaction forces 
The reaction forces in the support beams are converted into pressure on the skin panel using the known dimensions of the beam and the cutout of the door with following equations:

$$
\begin{gathered}
q=\frac{2 \cdot F_{R}}{l}=\frac{2 \cdot 30000}{1096}=54.75 \mathrm{Nmm}^{-1} \\
p=\frac{q}{a}=\frac{54.75}{300}=0.182 \mathrm{Nmm}^{-1}
\end{gathered}
$$

where $F_{R}[\mathrm{~N}]$ is reaction force in support beams, $l[\mathrm{~mm}]$ is length of the top hat beam, $q\left[\mathrm{Nmm}^{-}\right.$ $\left.{ }^{1}\right]$ is uniform load $a[\mathrm{~mm}]$ is width of the skin panel and $p[\mathrm{MPa}]$ is the inner pressure of the aircraft cabin exerted on to the fuselage.

Boundary conditions were set as follows (Fig. 3). BC1, BC2 and $\mathrm{BC} 3$ were all assigned to specific edge of the skin cutout. $\mathrm{BC} 1$ prevents the rotation around y (green) axis, $\mathrm{BC} 2$ prevents displacement in $\mathrm{z}$ (blue) axis, BC3 forbids displacement in direction of $\mathrm{y}$ and $\mathrm{x}$ (red) axis and a rotation around y axis. Two points (BC4) are fixed (no rotation and no displacement).

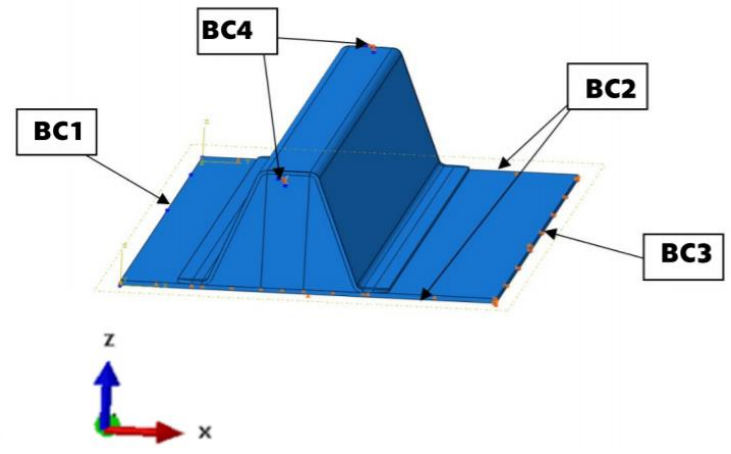

Fig. 3 Boundary conditions

Two types of elements were used in our calculations - the homogenized model used elements with linear elastic orthotropic material and the layered model used linear elastic lamina material. The size of elements was $1 \mathrm{~mm}$ along the length of the beam and along the top hat shape. There were three elements across the thickness of the beam. Mesh was later verified and sufficient.

\section{Geometry adjustments}

The following geometry options were analysed. Firstly, we have the basic top hat shape, as seen in Fig. 1, then a horizontal bar was added to the top hat beam (Fig. 4 left - "A" version). Next, one web of the two was curved instead of being straight (Fig. 4 right) The curved web is at the maximum (in the middle of the beam itself) bulged by $20 \mathrm{~mm}$ out of the beam. Lastly, as with the basic top hat, a horizontal bar was added to the top hat with curved web. All in all, one metal and four composite versions were computed.
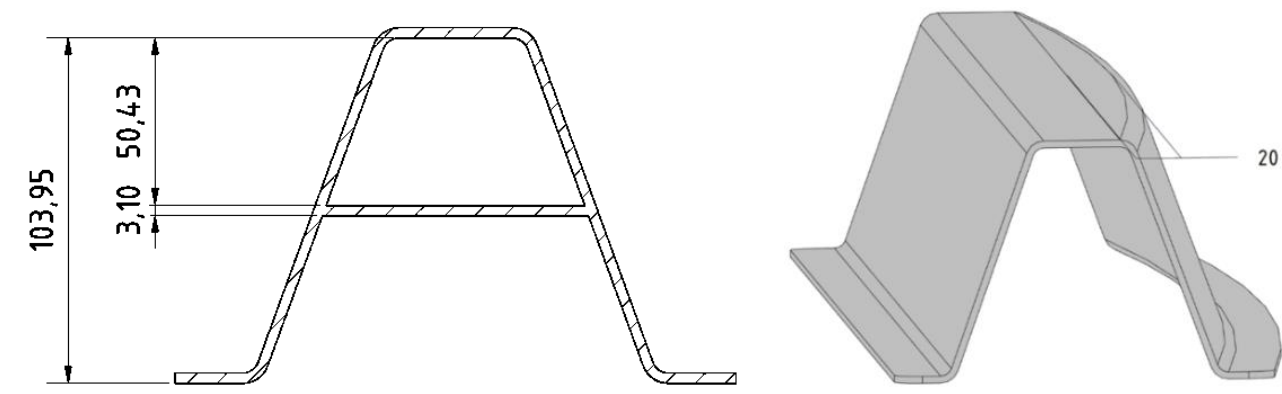

Fig. 4 Top hat with horizontal bar (left) and top hat with horizontal bar with curved web (right) 


\section{$4 \quad$ Stress and strain analysis}

Firstly, we used a duralumin top hat as a calibration and verification of our model. After applying the loading pressure, the assembly deforms as shown in Fig. 5. The figure shows the magnitude of deformations and is presented in millimetres. The maximum displacement of 6.1 $\mathrm{mm}$ is located in between the two beams. All visual deformations are for clarity scaled up with a factor of ten.

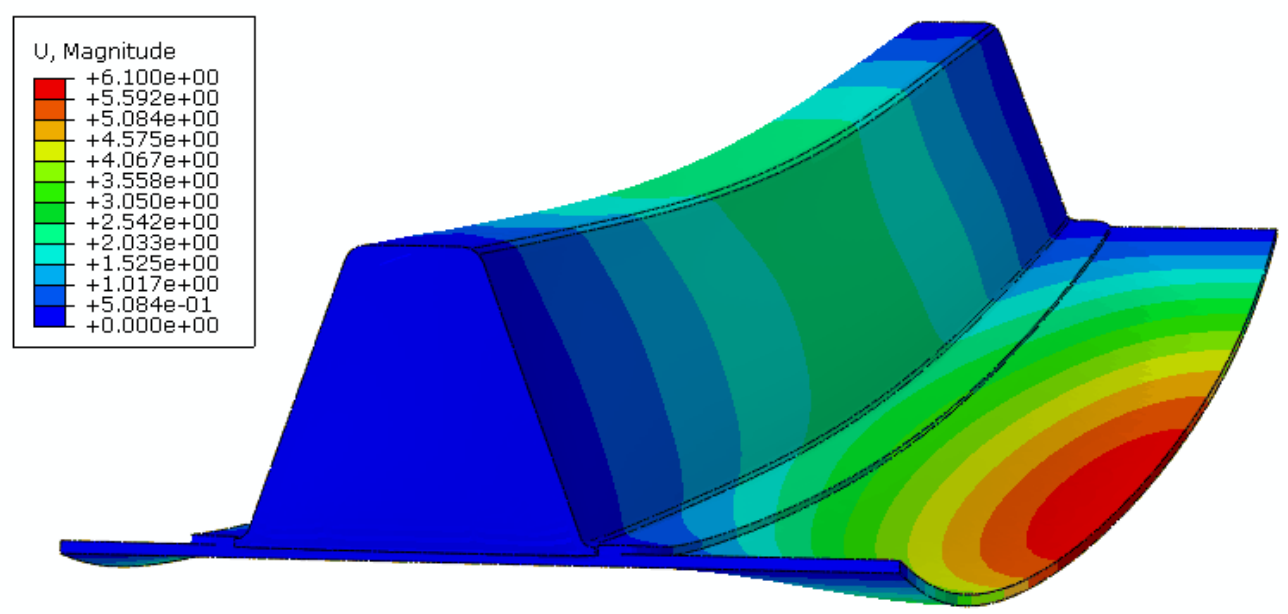

Fig. 5 Deformation of duralumin top hat beam (left)

Being done with the metal version, we moved on to analyse the different composite options. The assemblies deform similarly for all versions as in the metal example seen in Fig. 5, with the only difference in the magnitude of deformation. Since the deformed assembly looks similar in all cases only a table of results is provided (Table 2 in section 6).

\section{$5 \quad$ Buckling analysis}

Since the thickness of the beam is at $3.1 \mathrm{~mm}$ very small in comparison to other dimensions of the top hat, a buckling analysis was done in order to find out, whether the structure is prone to lose stability after the application of loading pressure. The first three eigenvalues were computed with corresponding eigenvectors for all types of geometry. The first eigenvector for composite top hat beam is in Fig. 6.

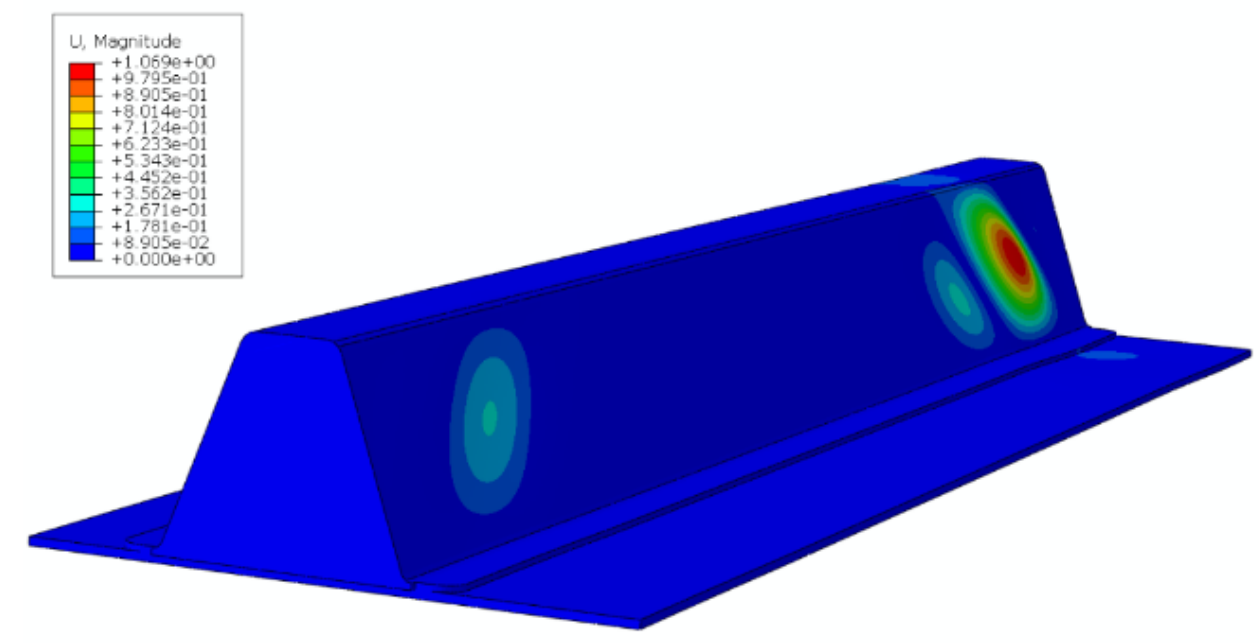

Fig. 6 First eigenvector for composite top hat beam with straight webs 
All three eigenvectors were similar in shape, the only difference was the position of the bulges. The most important of those three eigenvectors is for us the first one, since that is the eigenvector which would occur for the lowest loading pressure. The eigenvalue for the first eigenvector is $-0.7797 \mathrm{MPa}$, which tells us two things. Firstly, the minus before the number says, that the only way this eigenvector would appear is if the loading pressure was applied in the opposite direction. Secondly, even if our loading pressure was applied the other way, at $0.182 \mathrm{MPa}$ we would have a safety factor of 4.284 , a result desired when buckling is in question. Safety factor was computed as follows:

$$
k=\frac{p_{1}}{p_{s}}=\frac{0.7797}{0.182}=4.284[-]
$$

where $k$ is the safety factor, $p_{1}$ is the first eigenvalue and $p_{s}$ is our loading pressure [5].

Eigenvalues for other geometry versions are once again summarized in Table 2 in section 6.

\section{Summary of results}

The following table summarizes our computed results. The table shows the magnitude of maximum displacement $(\mathrm{mm})$, weight $(\mathrm{kg})$ of specific geometry option and first eigenvalue (MPa) of buckling.

Table 2 Displacement, strength and buckling result comparison

\begin{tabular}{|c|c|c|c|}
\hline $\begin{array}{c}\text { Model (S - straight webs, } \mathrm{C} \text { - curved } \\
\text { web) }\end{array}$ & $\begin{array}{c}\text { Maximum } \\
\text { displacement }[\mathrm{mm}]\end{array}$ & Weight $[\mathrm{kg}]$ & $\begin{array}{c}\text { First } \\
\text { eigenvalue } \\
{[\mathrm{MPa}]}\end{array}$ \\
\hline S-Duralumin & 6.1 & 2.93 & -0.95252 \\
\hline S-With homogenized properties & 7.287 & 1.7 & -0.7797 \\
\hline S-Layered versions & 7.377 & 1.7 & -0.80263 \\
\hline $\begin{array}{l}\text { S- "A" version with homogenized } \\
\text { properties }\end{array}$ & 6.720 & 2.13 & -0.93041 \\
\hline S- "A" layered version & 6.775 & 2.13 & -0.94142 \\
\hline C-With homogenized properties & 5.268 & 1.77 & -0.85868 \\
\hline C-Layered version & 5.207 & 1.77 & -0.82486 \\
\hline $\begin{array}{l}\text { C- "A" version with homogenized } \\
\text { properties }\end{array}$ & 4.916 & 2.27 & -0.95929 \\
\hline C- "A" layered versions & 5.003 & 2.27 & -0.98519 \\
\hline
\end{tabular}

We initially get a displacement of around $7.2 \mathrm{~mm}$ with the composite top hat with straight webs. We can get better results by adding a horizontal bar in the middle of the profile, which reduces the maximum displacement found in the assembly to approximately $6.7 \mathrm{~mm}$. Even greater reduction of displacement is a product of curving one of the webs of the top hat beam as shown in Fig. 4. The displacement is reduced to approximately $5.2 \mathrm{~mm}$, a maximum displacement even smaller than that of the duralumin top hat. This displacement can be reduced 
even more by adding a horizontal bar, which results in maximum displacement being just around $5 \mathrm{~mm}$.

As for the buckling, the structure should resist it in all geometry versions with high enough safety as every geometry option would succumb only to pressure applied in opposite direction.

All the examined versions of the beams were checked for failure using the criterium of maximum stress, Tsai - Hill, Tsai - Wu and Azzi - Tsai - Hill criterium [3]. All versions passed this check.

\section{CONCLUSION}

In this work, a composite beam with a top hat cross section was analysed. From the initial top hat three other geometry variations were drawn and put under analysis. Computations were done and the results were compared.

All in all, while other versions might be sufficient, the "A" option with one web curved stands out with its ability to both resist buckling and reduce the maximum displacement in the assembly to about $5 \mathrm{~mm}$. It's cross section hardly deforms, and the beam could probably withstand loads much higher than what they were computed for.

The computations were done using two different methods. The biggest difference between them, in terms of displacement, was in computation of the " $\mathrm{A}$ " curved top hat beam, where the difference between displacements was $1.73 \%$. In terms of buckling, the biggest difference appeared when computing the curved top hat beam without the supporting horizontal bar, where the difference between first eigenvalues was $3.9 \%$.

\section{ACKNOWLEDGEMENTS}

This work has been supported by project FV30033 of the Ministry of Industry and Trade of the Czech Republic and by the Grant Agency of the Czech Technical University in Prague, under grant No. SGS18/175/OHK2/3T/12.

\section{REFERENCES}

[1] Ranakoti, L. et al. "Natural fibers and biopolymers characterization: A future potential composite material", Strojnícky časopis - Journal of Mechanical Engineering 68 (1), 33 - 50, 2018. DOI: $10.2478 /$ scjme-2018-0004

[2] Choudhury, A. et al. "Effect of Lamination Angle and Thickness on Analysis of Composite Plate Under Thermo Mechanical Loading", Strojnícky časopis - Journal of Mechanical Engineering 67 (1), pp. 5 - 22, 2017. DOI: 10.1515/scjme-2017-0001

[3] LAŠ, V. "Mechanika kompozitních materiálů”, $2^{\text {nd }}$ ed. In Plzeň: Západočeská univerzita, 2008. ISBN 9788070436899

[4] AEROSPACE COMPOSITES Datasheet TenCate Cetex ${ }^{\circledR}$ PPS: Product type: PPS Thermoplastic Resin System (Polyphenylene Sulfide). Aircraft interiors expo [online]. Accessed 2019-03-08]. Available at: https://www.aircraftinteriorsexpo.com/_ novadocuments $/ 8392 ? \mathrm{v}=634671502121130000$

[5] "Abaqus analysis user's manual: Eigenvalue buckling prediction", Https://www.sharcnet.ca [online]. Wed April 28, 2010 [Accessed 2019-03-07]. Available at:https://www.sharcnet.ca/Software/Abaqus610/Documentation/docs/v6.10/books/usb/ default.htm?startat=pt03ch06s02at02.html 